\title{
Concentrated Animal Feeding Operations, Row Crops and their Relationship to Nitrate in Eastern lowa Rivers
}

\author{
Mark B. Weldon and Keri C. Hornbuckle \\ University of lowa, Department of Civil and Environmental Engineering, SC 4105 lowa City, IA 52240
}

\begin{abstract}
Concentrated animal feeding operations (CAFO) and fertilizer application to row crops may contribute to poor water quality in surface waters. To test this hypothesis, we evaluated nutrient concentrations and fluxes in four Eastern Iowa watersheds sampled between 1996-2004. We found that these watersheds contribute nearly $10 \%$ of annual nitrate flux entering the Gulf of Mexico, while representing only $1.5 \%$ of the contributing drainage basin. Mass budget analysis shows stream flow to be a major loss of nitrogen (18\% of total $\mathrm{N}$ output), second only to crop harvest (63\%). The major watershed inputs of nitrogen include applied fertilizer for corn (54\% of total $\mathrm{N}$ input) and nitrogen fixation by soybeans (26\%). Despite the relatively small input from animal manure $(\sim 5 \%)$, the results of spatial analysis indicate that row crop and CAFO densities are significantly and independently correlated to higher nitrate concentration in streams. Pearson correlation coefficients of 0.59 and 0.89 were found between nitrate concentration and row crop and CAFO density, respectively. Multiple linear regression analysis produced a correlation for nitrate concentration with an $\mathrm{R}^{2}$ value of $85 \%$. High spatial density of row crops and CAFOs are linked to the highest river nitrate concentrations (up to $15 \mathrm{mg} / \mathrm{l}$ normalized over five years).
\end{abstract}

\section{Keywords}

nutrients; water quality; manure management; nonpoint pollution

\section{INTRODUCTION}

Heavily agricultural regions in the central U.S. often suffer from high concentrations of nutrients in surface waters $(1,2)$. Surface water impairments from high nutrient concentrations include human health risks for consumption, elevated costs for water treatment, anoxia, and reduced biological diversity (3). Iowa is a prime example of this situation as Iowa's rivers have among the highest nitrate and phosphorus concentrations in the central US (See Figure S-1). Nitrate is not efficiently removed by conventional drinking water treatment, and as a result the Des Moines Water Works activates a nitrate removal system during times of potentially high nitrate in their source water from the Des Moines and Racoon Rivers (4). Iowa waters discharge to the Mississippi River where elevated nutrients cause an extensive region of low dissolved

\footnotetext{
*Author to whom correspondence should be sent keri-hornbuckle@uiowa.edu phone: (319)384-0789 Fax: 319.335.5660; markweldon@uiowa.edu.

SUPPORTING INFORMATION One figure and five tables are included as supporting information. Figure S-1 is a recreation of results from Goolsby et al. (1) showing mean nitrate concentration for 24 rivers in the Mississippi-Atchalafaya River basin; Table S-1 lists water sample measurements, test methods and uncertainties for this study; Table S-2 lists the land cover categories used in the creation of the landscape variables; Tables S-3 and S-4 show referenced rate factors used in the nitrogen mass budget; and Tables S-5 and S-6 show Pearson correlation coefficients between landscape variables and nutrient concentrations and fluxes respectively.

BRIEF High nitrate concentrations in Eastern Iowa rivers are correlated with high spatial densities of row crops and CAFOs.
} 
oxygen concentrations in the northern Gulf of Mexico near the Louisiana coast (5). In the Gulf of Mexico the hypoxic zone has devastated local shellfish populations and driven fish populations to other waters (6). Goolsby et al. estimated nitrogen flux to the Gulf of Mexico to be 1.6 million metric tons per year (61\% nitrate, $37 \%$ organic nitrogen, $2 \%$ ammonium) and phosphorus flux to be 136,000 metric tons per year (69\% particulate or organic, $31 \%$ dissolved orthophosphate) (1).

Riverine nitrate fluxes are closely linked to anthropogenic inputs of nutrients to the watershed, over both spatial and temporal scales. For the lower Mississippi River system, McIsaac et al. showed that almost all (up to 95\%) of the temporal variability in nitrate flux between 1960 and 1998 can be explained by variations in the net anthropogenic nitrogen input $(7,8)$. Libra et al. performed a similar accounting of nitrogen and phosphorous but for the smaller study area of Iowa watersheds (9). Total nitrogen input was most strongly correlated with stream nitrate concentration although the use of chemical fertilizer and the percentage of row crops in the watershed were significant. Arbuckle and Downing have shown that that nitrogen:phosphorus ratios in Iowa lakes are linked to the spatial distribution of row crop and pasture land use in watersheds (10). Schilling and Libra developed a model correlating stream nitrate concentration as a function of row crop land use percentage (11). McIsaac and Hu showed that the presence or absence of tile drainage can be associated with variations of nutrient fluxes in surface waters (12). It is clear that land use for row crops is widely associated with increased nutrient concentrations and fluxes.

Agriculture is more than just row crops. Pasture-based livestock has traditionally been a significant component of the agricultural landscape. Recently however, concentrated animal feeding operations (CAFOs) have begun to replace pasture-based livestock operations, beginning in the 1950s for cattle and poultry and the 1970s for swine (13). Manure management from CAFOs includes application to nearby crop land and may be applied at a higher rate than can be assimilated by crop requirements $(13,14)$. This may result in increased fluxes and concentrations of nutrients in surface waters. Manure spills from CAFO waste storage failures also lead to significant pollution events into natural water bodies (15). In North Carolina, hurricanes have caused catastrophic failures and tremendous nutrient releases from CAFO waste storage systems (15). We know of no studies, however, that examine the relationship between water quality and typical (long-term) operations of CAFOs within the agricultural landscape.

The purpose of this study is to determine if CAFOs have an impact on river nutrient content that can be isolated through a spatial analysis of land use and water quality data. Iowa is an ideal place to study the relationship between CAFOs and water quality. It is a heavily agricultural state and recently led the nation in agricultural production of corn, soybeans, hogs and eggs (16). There are more than 3800 CAFOs in Iowa and these operations are becoming more concentrated spatially (17).

\section{EXPERIMENTAL SECTION}

Our study area, the Eastern Iowa Study Area (EISA), includes the Cedar, Iowa, Skunk and Wapsipinicon river basins. It is essentially the same area used in USGS water quality assessments $(18,19)$ and identified there as EIWA. The study area is large enough to include the human activities and ecological functions that are of interest in this research. It contains enough monitoring stations to allow comparisons both within and between watersheds. Figure 1 shows the EISA including urban areas, monitoring stations and rivers.

We identified 37 monitoring stations within the EISA that have a temporal data record of at least 40 months. We also include one station, the Skunk River at Augusta with 31 months of 
data, because of its location near the mouth of the Skunk River representing the entire Skunk River basin. This gives us a total of 38 monitoring stations and one station in each basin that is representative of the entire basin. Table 1 shows the number of monitoring stations in each of the four watersheds and their average temporal records. Water samples are typically taken once per month so we required a 40 month record to lessen the impacts of short-term weather variability. Since most sites had 5 years of data, we normalized mass fluxes on a 60 month basis to allow comparison between stations with differing temporal record lengths.

The 38 monitoring stations are distributed as a network over the landscape. We segregated the data from the 38 stations into independent and dependent stations. We categorized stations located on the upper reaches of the river systems, with no other stations above them, as independent. Stations downstream of other stations are dependent as water samples taken from these stations may be influenced by conditions at upstream stations. Seventeen of the stations in our study area are independent and the focus of this study.

We hypothesized that CAFOs and nutrient concentrations and fluxes were positively correlated and the relationship could be determined independent of other major sources of nutrients. Our methodological approach was organized into five steps: Water quality data database development; nutrient flux analysis; creation of landscape variables; nitrogen mass budget; and statistical correlation and regression analysis.

River water quality data in the form of nutrient concentrations and flows were available from the Iowa Department of Natural Resources' (IDNR) STORET Ambient Water Quality Database and from USGS reports. From this raw data, we produced estimates of mass fluxes, concentrations and mean stream flows. Our data cover the time period from 1996 to 2004 with the majority of the data collected in the 1999-2004 time period. Both nutrient concentrations and mass fluxes are of substantial interest. Nutrient concentrations are the primary factors when considering the quality of aquatic habitat or drinking water sources. Mass fluxes are the primary factors when considering issues such as nutrient transport to the Gulf of Mexico.

Samples for the STORET program are collected and analyzed by the University of Iowa Hygienic Laboratory (UHL). Samples are collected by an individual visiting each site and collecting a grab sample. Flow measurement at the time of sampling is made either by reference to a nearby gauging station or by manual measurement following established IDNR procedures. Quality assurance and quality control guidelines are established as a normal part of UHL operations (See Table S-1 in Supplementary Information for method references and uncertainties). Approximately 10-15\% of the samples collected are blank or split samples for the purpose of monitoring measurement procedures and techniques.

To create landscape variables, we first delineated the drainage area associated with each monitoring station. This was done within a geographic information system (ESRI Arc Suite version 9.0) by overlaying the stream network and monitoring station locations on the level 12 HUC watershed map. The level 12 HUC maps represent a fine scale of resolution. Starting with the monitor furthest upstream on the stream network, level 12 basins were selected that drain to the selected station. This collection of areas was saved as a new file to be used later as an identification template. This process continued for each station downstream on the network, with previously selected areas excluded from the area for the station under consideration. This process delineated each watershed into areas uniquely associated with one monitoring station.

Landscape variables were created by identifying and counting land usage types, including agricultural activities, that occur within the boundaries of each monitoring station drainage area. Land use data is categorized into 17 different land use types including wetlands, forested areas, cropland, urban areas, etc. (see Table S-2 for a complete list). This data is available from 
the IDNR as a GIS grid file with 15 meter x 15 meter resolution and $+/-30$ meter accuracy. It is based on satellite imagery from Landsat 5 and Landsat 7 taken from May 13, 2002 through May 27, 2003. Two images were acquired for each area, one from a spring time frame, the second from a summer date. Nearly cloud-free images were acquired in almost all cases. Using the GIS, the monitoring basins are overlaid on the land use grid such that the land use grid cells can be counted for each land use category within each monitoring station basin. The number of CAFOs are counted in a similar fashion, except the monitoring basin boundaries are overlaid a different GIS file which contains CAFO location and size data. This file includes the number and type of animals raised at each CAFO. Landscape variables were divided by the total acreage for each station area to calculate density values for each landscape variable.

We created a mass budget for nitrogen in the EISA based on preliminary results indicating nitrate to be the most highly correlated water quality component in our dataset. Nitrogen input and output fluxes were estimated for each monitoring station drainage basin using landscape information gathered in the creation of the landscape variables. Nitrogen inputs included inorganic fertilizer, manure, nitrogen fixation and deposition. Outputs included the nitrogen content of crops, nitrogen loss through volatilization mechanisms and nitrogen leached to streams. Our analysis centered on agricultural land and considered the main nitrogen fluxes that were applied to the land or evolved from the land. We did not include microbial nitrogen transformations that occur within soil due to the small net effect of these activities $(8,9,12)$.

Finally, we linked the water quality data with the landscape variables. The data were checked for correlation between water quality parameters and landscape variables. Highly correlated parameters were further analyzed via multiple regression analysis to identify the strength of relationship between the landscape variable and water quality parameter.

\section{RESULTS and DISCUSSION DATABASE DEVELOPMENT}

Our water quality database for the EISA contains stream flow and mass flux and concentration estimates for elemental phosphorus, orthophosphate, total suspended solids, total Kjeldahl nitrogen, nitrate plus nitrite, ammonia nitrogen, organic nitrogen, total nitrogen and total phosphorus. Nutrient concentration is reported as $\mathrm{mg} / \mathrm{l}$ of the nutrient ( $\mathrm{N}$ or $\mathrm{P}$ ). The database includes monthly sample information for 38 water monitoring stations with an average temporal record length of 60.1 months (standard deviation $=11.3$ months). There are a few instances of multiple samples in a month. In these cases, the data are averaged to produce a single monthly mass flux estimate. Station mass flux estimates are summed over the length of the data record and then normalized to a 60 -month basis by multiplying the summed flux by 60 and dividing by the number of months in the data record. This was done to facilitate comparisons between stations. Station concentration estimates are calculated by dividing the summed mass flux by the total stream flow.

\section{NUTRIENT FLUX ANALYSIS}

Our nutrient flux analysis shows that the EISA is a major contributor of nitrate to the Gulf of Mexico, exporting approximately 91,000 metric tons per year. Table 2 shows our estimates of average annual nitrate and total phosphorus flux and concentration from the four river basins of the EISA along with comparable estimates from Goolsby et al.(1) and Libra et al.(9). Estimates are reported at multiple locations for the Cedar and Iowa Rivers in order to offer direct comparison with estimates from Goolsby et al. and Libra et al.

The flux estimates show reasonable agreement, considering that they represent three different time periods. Our data comes from the 1996-2004 time period, the data of Goolsby et al. come 
from the 1980-1996 time period and the data for Libra et al was based on data from 1999-2001. Our concentration data show a significant increase when compared to Goolsby et al. While our research is not specifically targeted toward temporal differences, the data suggest that nutrient concentrations in our study area have become greater over time, which is consistent with Goolsby et al.'s reported historical increase in nitrate concentration in the Cedar River in the $20^{\text {th }}$ century (Figure 2 ).

The EISA total of 91,513 metric tons per year (MT/yr) of nitrate can be compared to Goolsby's estimate for nitrate flux for the entire Mississippi and Atchafalaya River basin (MARB) of $950,000 \mathrm{MT} / \mathrm{yr}$ (1.6 million MT/yr, with $61 \%$ being nitrate). Therefore, as much as $9.6 \%$ of the annual nitrate flux entering the Gulf from the Mississippi River can be attributed to the EISA, while the EISA represents only $1.5 \%$ of the land area of the MARB. Likewise, the EISA total phosphorus flux of 8,395 MT/yr represents over 6\% of Goolsby's estimate of 136,000 MT/yr for the MARB.

\section{NITROGEN BUDGET}

Our nitrogen budget is based on the land use within each sub-watershed. Knowing the number of acres planted to different crops, and knowing the location and size of CAFOs, permitted us to estimate nitrogen fluxes to and from each hectare of land within the sub-watershed. We used rate factors that were applicable to the EISA, as reviewed and reported by Libra et al (9), but also from Illinois data from McIsaac et al. (8), the United States Department of Agriculture (20), and the IDNR. Rate factors and literature source for each of the flux categories are listed in supplementary information Tables S-3 and S-4 and briefly summarized here. Fertilizer nitrogen was based on application to all corn acres within each sub-watershed at a rate of 150 lbs. N per acre as reported to the IDNR. We assumed no fertilizer was applied to soybeans. Manure nitrogen ranged from $0.003 \mathrm{lb} \mathrm{N} / \mathrm{d}$ for chickens to $0.7 \mathrm{lbs} / \mathrm{d}$ for dairy cows (9). We estimated nitrogen flux from manure for each sub-watershed by multiplying these factors by the number of animals at each CAFO and then by suitable loss factors to account for nitrogen lost to the atmosphere from the CAFO buildings and from the application of manure. Nitrogen fixation was based on factors for soybeans (100 kg/ha), alfalfa (200 kg/ha) and hay (100 kg/ ha) (9). Nitrogen deposition was estimated as the sum of wet and dry deposition mechanisms (21).

Nitrogen export in crops was based on the average crop yields from 1988-2004 (20) multiplied by the nitrogen content of each crop. Nitrogen loss through volatilization was based on crop senescence emissions, fertilizer application emissions and manure application emissions of nitrogen $(8,9)$. Nitrogen leaching to streams was calculated from our EISA water quality database.

Figure 3 shows the EISA nitrogen balance and fair agreement between inputs and outputs. The largest fluxes are fertilizer application and nitrogen fixation for the inputs and nitrogen export in crops for the outputs. Manure application represents a minor flux in this mass balance. Nitrogen lost to stream flow is significant at $18 \%$ of the total output. Total annual nitrogen inputs is expected to fall within the range 9.6 - 12.2 metric tons per square kilometer (MT/ $\mathrm{km}^{2}$ ), while total annual nitrogen outputs is expected to fall within the range $12.7-14.8 \mathrm{MT} /$ $\mathrm{km}^{2}$. The net mean imbalance is $136,000 \mathrm{MT} / \mathrm{yr}$ excess annual exports.

The uncertainty factors included within Figure 3 are intended to show the relative uncertainty for each flux category and represent the authors' best judgment. The observed imbalance between inputs and outputs $(21 \% \pm 12 \%)$ is large relative to that which might be expected to arise from the component errors. This suggests that there may be errors in the rate factors used or that there may be an unidentified input flux. We believe that most of the uncertainty lies in the fixation category among the inputs and the volatilization category among the outputs. It is 
also possible that local redeposition of atmospheric emissions from CAFO buildings and waste storage lagoons is a significant unidentified input flux to the budget.

The nitrogen budget shows manure to be a small factor in the overall budget and far overshadowed by fertilizer applied to corn and nitrogen fixed by legumes. This is somewhat contradictory to the results of correlation and regression analyses which will show CAFOs and animal units to be important factors in explaining nitrogen concentration in rivers.

\section{CORRELATION ANALYSIS}

Correlation analysis was employed to select landscape variables with strong Pearson Correlation Coefficients (PCC) corresponding to probability values (P-value) of $5 \%$ or less. Examination of parameter concentrations indicated a strong relationship between nitrate and the number of CAFOs $(\mathrm{PCC}=.627, \mathrm{P}$-value $=0.007)$, Animal Units $(\mathrm{PCC}=.756, \mathrm{P}$-value $=$ $0.000)$, CAFO Density $(\mathrm{PCC}=.885$, P-value $=0.000)$, Animal Unit Density $(\mathrm{PCC}=.891, \mathrm{P}$ value $=0.000)$ and Row Crop Density $(\mathrm{PCC}=.585$, P-value $=0.014)$. Total nitrogen is also correlated with these variables. Row Crop Density is negatively correlated with Ammonia $(\mathrm{PCC}=-.559, \mathrm{P}$-value $=0.020)$, Elemental Phosphorus $(\mathrm{PCC}=-.608, \mathrm{P}$-value $=0.010)$, Total Phosphorus $(\mathrm{PCC}=-.583, \mathrm{P}$-value $=0.014)$ and Total Suspended Solids $(\mathrm{PCC}=-.663, \mathrm{P}$ value $=0.004)$.

Correlation analysis of parameter mass fluxes indicated a moderate relationship between nitrate and row crop acres $(\mathrm{PCC}=.537, \mathrm{P}$-value $=0.026)$. Once again row crop density is negatively correlated with Elemental Phosphorus $(\mathrm{PCC}=-.461, \mathrm{P}$-value $=0.010)$ and Total Suspended Solids $(\mathrm{PCC}=-.598$, P-value $=0.011)$. In general, correlation values are stronger for concentration data than for mass flux data (See Table S-5 and S-6 in Supplementary Information).

The high correlation between nitrate concentration and animal unit density suggest that CAFOs produce measurable impacts to water quality. Of all the water quality parameters examined, nitrate was found to be the most responsive to livestock and row crop agricultural activities at the watershed scale. This led us to choose nitrate as the dependent variable for multiple regression analysis. Correlation analysis also indicated that the agricultural variables of livestock production and row crop acreage are best represented as respective densities, and the regression analysis uses them in this form. While this transformation improves correlation moderately for livestock it improves correlation markedly for row crops. These improvements related to density suggest that nitrate fate, flux and flow paths are influenced by local landscape characteristics and that it is possible to overwhelm the landscape's potential for assimilating nitrate before it reaches the river network.

Except for ammonia (present as dissolved ammonium ion), the water quality parameters that have negative correlations with row crop density are particle associated parameters. This suggests that soil conservation measures on intensively managed croplands may be having a positive impact. The ammonia results may also be related to soil conservation since oxidation of ammonia to nitrite and nitrate occurs in the soil.

\section{REGRESSION ANALYSIS}

Regression analysis was performed on nitrate concentration and CAFOs, animal unit and row crop densities. Simple linear regression showed a strong relationship between nitrate concentration and animal unit density $\left(\mathrm{R}^{2}=79.4 \%\right)$ and a moderate relationship for nitrate concentration and row crop density $\left(\mathrm{R}^{2}=34.2 \%\right)$. We then employed multiple linear regression analysis to examine both animal unit density and row crop density together. This improved the 
strength of the relationship by accounting for approximately $5 \%$ more of the variability. The regression equation and $\mathrm{R}^{2}$ value in this case are:

Nitrate concentration $\quad(\mathrm{mg} / \mathrm{l})=2.39+7.65 \quad$ Animal Unit Density+7.01 Row Crop Density

$\mathrm{R}^{2}=84.8 \%$

Equation 1

Equation 1 explicitly recognizes the modern duality of row crop agriculture and CAFOs, much like Arbuckle and Downing's (10) consideration of row crop and pasture lands. While the percentages of land in row crops and pasture are inversely related, modern livestock operations (CAFOs) typically vary directly with row crop density out of the practical concern of manure disposal. Equation 1 also complements and extends Schilling and Libra's (11) finding that river nitrate concentration can be approximated as 0.1 times the watershed's row crop percentage.

The relationship between nitrate, animal unit density and row crops is displayed in Figure 4. The 5 year normalized nitrate concentration clearly increases with both animal unit and row crop densities, and exceeds the USEPA limit of $10 \mathrm{mg} / \mathrm{l}$ for drinking water (22) in some cases. The two sub-watersheds in the upper right of Figure 4 have nitrate concentrations greater than $15 \mathrm{mg} / \mathrm{l}$. In our data set, animal unit density ranges from near zero to 1.07 and row crop density ranges from 0.47 to 0.81 . Higher animal unit densities occur only at high row crop density whereas high row crop density occurs at high or low animal unit density. The situation of high animal unit density at low row crop density does not occur in our data set.

Correlation and regression analyses point to animal unit density, and therefore CAFO density, as a prime indicator of nitrate concentration in streams. This stands in marked contrast to the nitrogen budget analysis which did not identify manure as a large factor in the total budget. One possible explanation to this apparent contradiction is that manure application practices permit excessive leaching of nitrogen to streams. Other possible explanations are that local atmospheric deposition of nitrogen from CAFO buildings is a significant nitrogen pathway or that plant uptake of nitrogen from manure is somehow inhibited. These issues of manure nitrogen management have been discussed by other researchers $(13,14,23)$ as well and warrant further quantitative investigation.

The development of a water quality database linked to agricultural parameters by stream monitoring station allows us to analyze the impacts of local agricultural practices within the EISA. For example, drainage tiling has been shown to be an important factor in nitrogen flux to streams from some agricultural lands (12). We considered tiling as a potential landscape variable for this research but were unable to obtain a data set of sufficient accuracy at the subwatershed scale to warrant its inclusion. With further refinement however, an accurate dataset of tiled lands could be incorporated into the database.

Our research suggests that restricting nitrate to no more than $10 \mathrm{mg} / \mathrm{l}$ in eastern Iowa rivers may require a combined limitation of livestock and row crop agricultural densities. In our study area, the two instances of very high animal unit density were associated with nitrate concentrations above $15 \mathrm{mg} / \mathrm{l}$. High row crop densities were associated with nitrate concentrations in the $9-10 \mathrm{mg} / \mathrm{l}$ range. At animal unit densities less than 0.2 and row crop densities less than 0.6 , nitrate concentrations were in the $6-7 \mathrm{mg} / \mathrm{l}$ range.

Agricultural densities are not currently used as a decision making tool with regard to permitting agricultural activities under Iowa law. Rather, Iowa law focuses on local conditions for CAFO permitting, typically separation distances between CAFO sites and other land uses such as residences, public buildings, water or agricultural drainage wells and streams (24). State requirements do include preparation of manure management plans indicating the availability of land for manure application. This local focus however doesn't fully account for spatial 
concentrations of agricultural activities that we found to be important. Consideration of the agricultural - environmental linkages at the watershed scale may be a beneficial addition to our current regulatory approach to CAFOs.

\section{Supplementary Material}

Refer to Web version on PubMed Central for supplementary material.

\section{ACKNOWLEDGEMENTS}

The authors would like to thank the Iowa Department of Natural Resources, particularly the Iowa City Geologic Survey Office for providing basic water quality and GIS data sets. We are also grateful to the U.S. Geologic Survey and the University of Iowa Hygienic Laboratory for water quality information. Technical assistance was provided by the University of Iowa Statistical Consulting Center. We appreciate the financial support of the University of Iowa Graduate College.

\section{REFERENCED LITERATURE}

(1). Goolsby, DA.; Battaglin, WA.; Lawrence, GB.; Artz, RS.; Aulenbach, BT.; Hooper, RP.; Keeney, DR.; Stensland, GJ. Flux and Sources of Nutrients in the Mississippi-Atchafalaya River Basin (Report of Task Group 3 to the White House committee on Environment and Natural Resources, Hypoxia Work Group, Federal Register [0097-6326]. 1999.

(2). U.S. Department of the Interior. The Quality of Our Nation's Waters. U.S. Geological Survey, Circular 1225. 1999

(3). Carpenter SR, Caraco NF, Correll DL, Howarth RW, Sharpley AN, Smith VH. Nonpoint pollution of surface waters with phosphorus and nitrogen. Ecological Applications 1998;8:559-568.

(4). Des Moines Water Works. 2003 Consumer Confidence Report. www.dmww.com

(5). Rabalais NN, Wiseman WJ, Turner RE, SenGupta BK, Dortch Q. Nutrient changes in the Mississippi River and system responses on the adjacent continental shelf. Estuaries 1996;19:386-407.

(6). Rabalais NN, Turner RE, Wiseman WJ. Gulf of Mexico Hypoxia, A.K.A. The Dead Zone. Annual Review of Ecological Systems 2002;33:235-263.

(7). McIsaac GF, David MB, Gertner GZ, Goolsby DA. Eutrophication - Nitrate flux in the Mississippi river. Nature 2001;414:166-167. [PubMed: 11700544]

(8). McIsaac GF, David MB, Gertner GZ, Goolsby DA. Relating net nitrogen input in the Mississippi River basin to nitrate flux in the lower Mississippi River: A comparison of approaches. J. Environ. Qual 2002;31:1610-1622. [PubMed: 12371178]

(9). Libra, RD.; Wolter, M.; Langel, RJ. Nitrogen and Phosphorous Budgets for Iowa and Iowa Watersheds. Iowa Geological Survey Technical Information Series 47. Dec. 2004 http://www.igsb.uiowa.edu/gsbpubs/pdf/TIS-47.pdf

(10). Arbuckle KE, Downing JA. The influence of watershed land use on lake N : P in a predominantly agricultural landscape. Limnol.Oceanogr 2001;46:970-975.

(11). Schilling KE, Libra RD. The relationship of nitrate concentrations in streams to row crop land use in Iowa. J. Environ. Qual 2000;29:1846-1851.

(12). McIsaac GF, Hu XT. Net N input and riverine N export from Illinois agricultural watersheds with and without extensive tile drainage. Biogeochemistry 2004;70:251-271.

(13). Mallin MA, Cahoon LB. Industrialized animal production - A major source of nutrient and microbial pollution to aquatic ecosystems. Population and Environment 2003;24:369-385.

(14). Keeney DR, Gilbert EM. Swine manure management plans in north-central Iowa: Nutrient loading and policy implications. J. Soil and Water Cons 2000;55:205-212.

(15). Mallin MA. Impacts of industrial animal production on rivers and estuaries. American Scientist 2000;88:26-37.

(16). U.S. Department of Agriculture National Agricultural Statistics Service. Bulletins 980a, 982, 986. http://www.nass.usda.gov/nass/pubs/histdata.htm 
(17). U.S. Department of Agriculture National Agricultural Statistics Service. Bulletin 1002. http://www.nass.usda.gov/nass/pubs/histdata.htm

(18). Akers, K.; Schnoebelen, D.; Savoca, M.; Roberts, L.; Becher, K. Water Quality Assessment of the Eastern Iowa Basins: Hydrologic and Biologic Data, September 1995 through September 1996. United States Geological Survey. 1999. USGS Open-File Report 99-66

(19). Akers, K.; Montgomery, D.; Christiansen, D.; Savoca, M.; Schnoebelen, D.; Becher, K.; Sadorf, E. Water Quality Assessment of the Eastern Iowa Basins: Hydrologic and Biologic Data, October 1996 through September 1998. United States Geological Survey. 2000. USGS Open-File Report 99-66

(20). U.S. Department of Agriculture. Iowa Agricultural Statistics. National Agricultural Statistics Service. http://www.nass.usda.gov/ia/historics

(21). National Atmospheric Deposition Program. http://nadp.sws.uiuc.edu/

(22). U.S. Environmental Protection Agency. List of Drinking Water Contaminants \& MCL's. 2002. EPA 816-F-02-013http://www.epa.gov/safewater/mcl.html

(23). Karr JD, Showers WJ, Gilliam JW, Andres AS. Tracing nitrate transport and environmental impact from intensive swine farming using delta nitrogen-15. J. Environ. Qual 2001;30:1163-1175. [PubMed: 11476493]

(24). Iowa State Legislature. An Act Relating to Animal Agriculture, Providing for Fees, Providing for Penalties, and Including Retroactive Applicability and Effective Date Provisions. Senate File 2293 


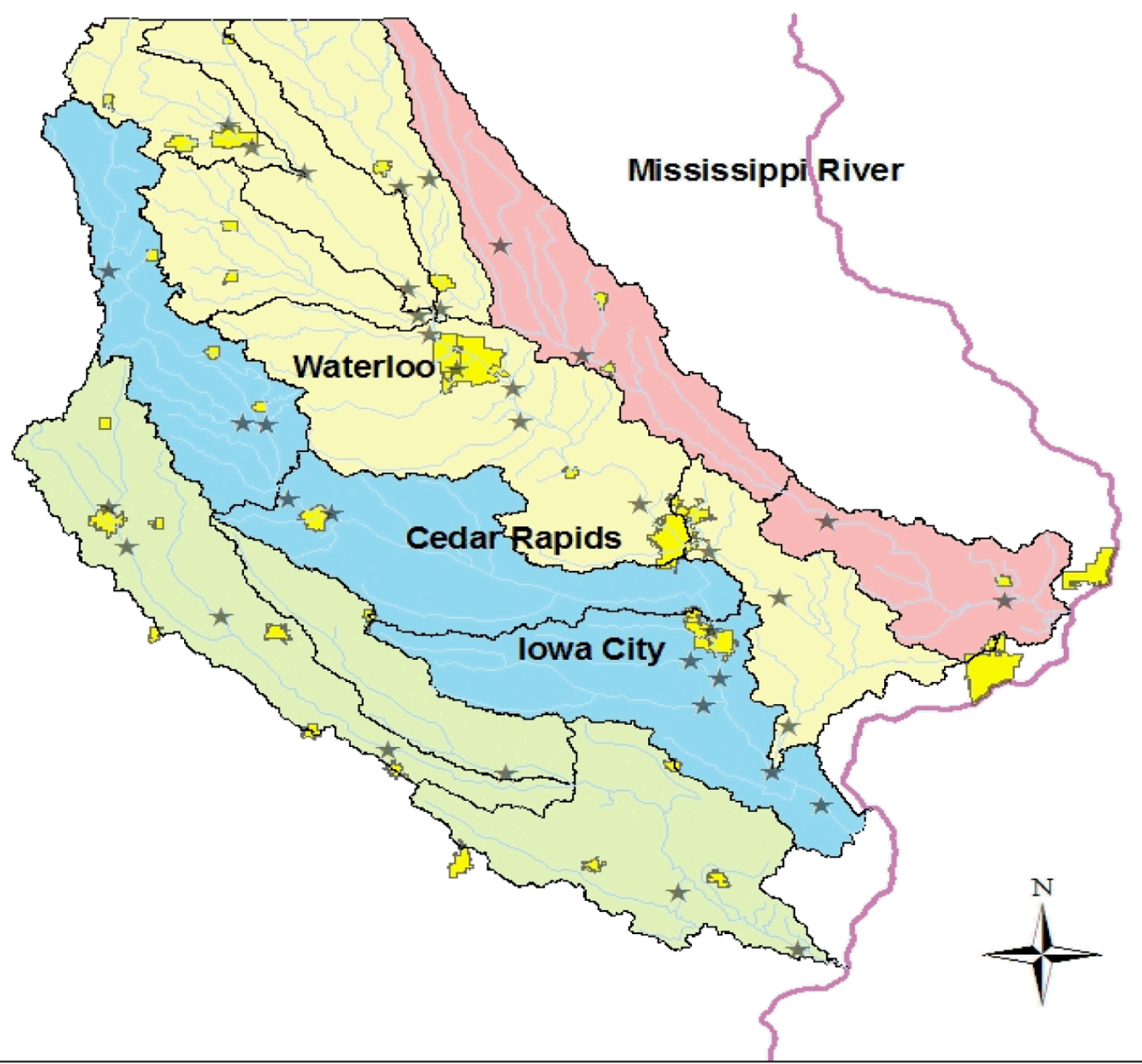

Figure 1.

Eastern Iowa Study Area. The four major watersheds include the Wapsipinicon (pink), the Cedar (pale yellow), the Iowa (blue) and the Skunk (light green). The monitoring stations are shown by stars and urban areas are shown in bright yellow. 


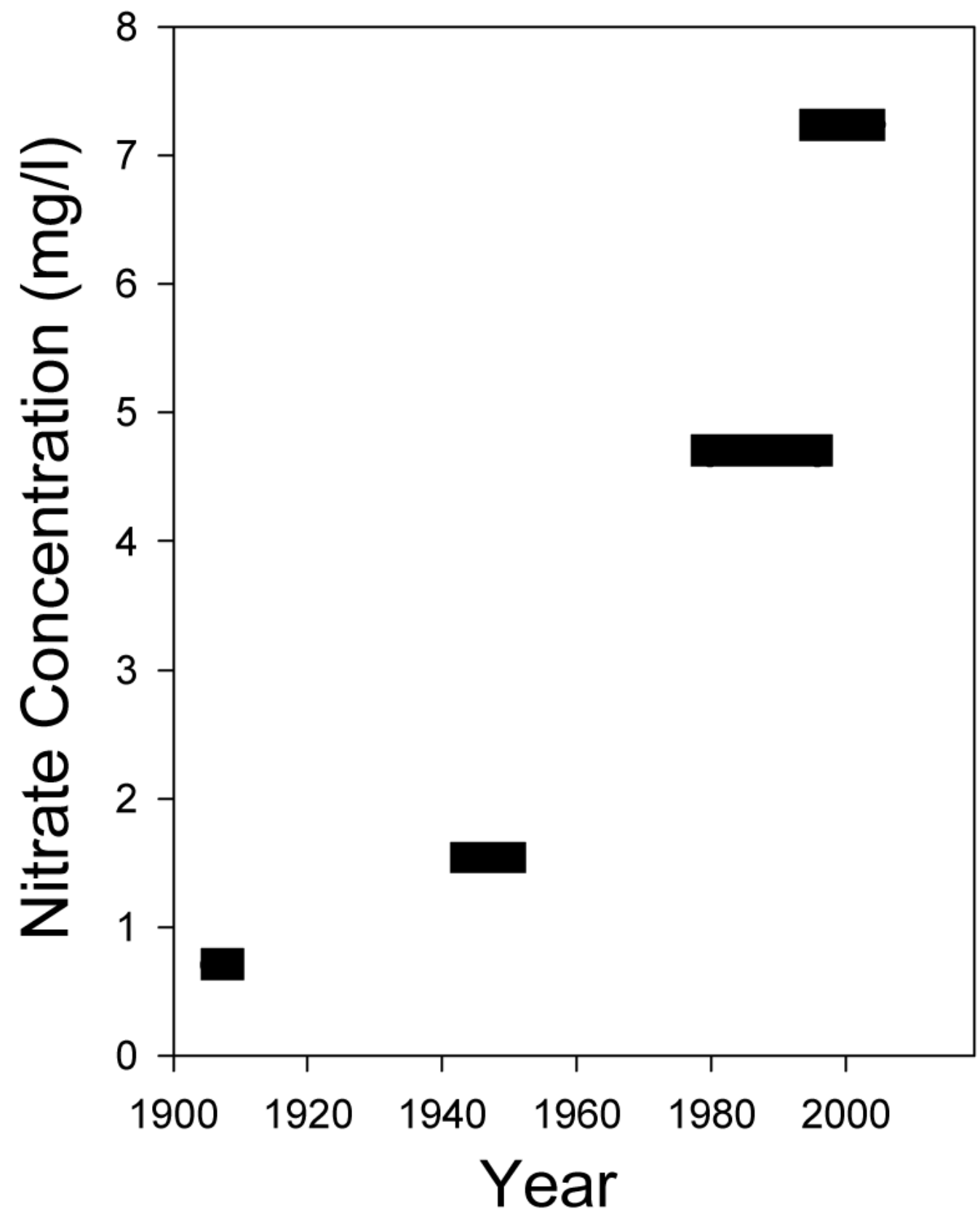

Figure 2.

Average concentration of nitrate concentrations in the Cedar River. The samples collected between 1996 and 2004 are the data described in this study. All other data is from Goolsby et al, 1999 (1). 

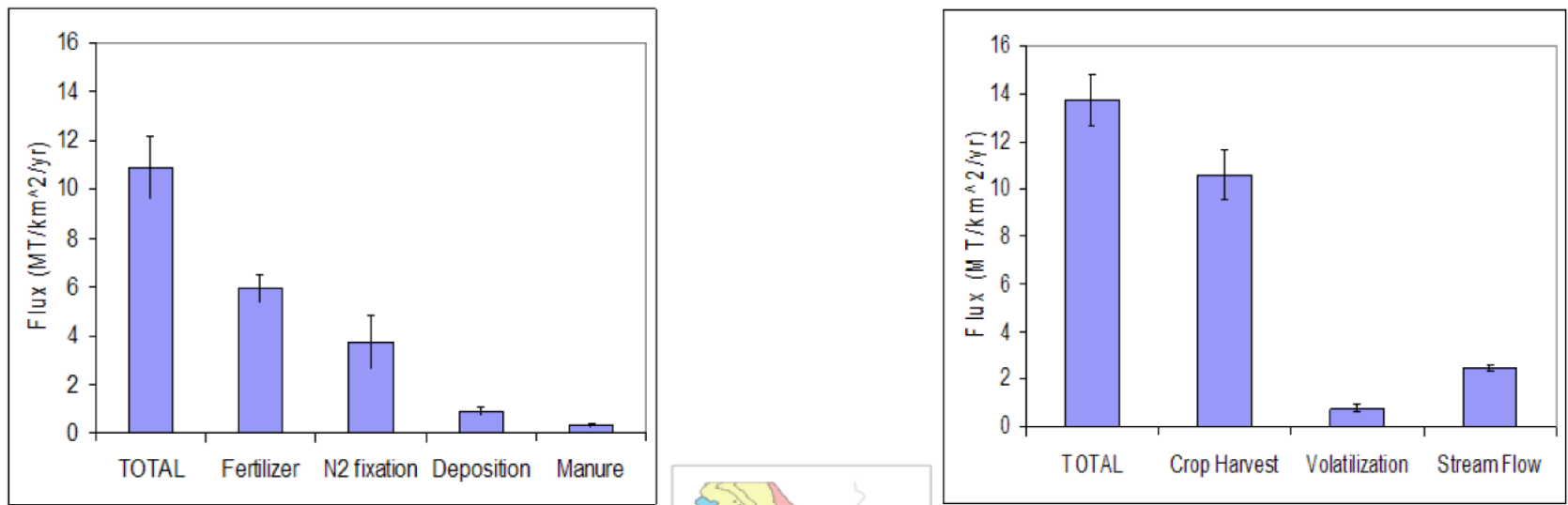

Nitrogen Inputs (MT/km²/yr)

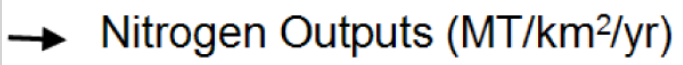

\begin{tabular}{|l|l|l|}
\hline Fertilizer & Corn & $5.92+/-0.59$ \\
\cline { 2 - 3 } & Soybeans & $0.00+/-0.00$ \\
\hline \multirow{3}{*}{ Fixation } & Soybeans & $2.82+/-0.85$ \\
\cline { 2 - 3 } & Alfalfa & $0.50+/-0.15$ \\
\cline { 2 - 3 } & Hay & $0.42+/-0.13$ \\
\hline \multirow{3}{*}{ Meposition } & Wet & $0.52+/-0.10$ \\
\cline { 2 - 3 } & Dry & $0.37+/-0.07$ \\
\hline & Cattle & $0.04+/-0.01$ \\
\cline { 2 - 3 } & Swine & $0.21+/-0.04$ \\
\cline { 2 - 3 } & Chickens & $0.06+/-0.01$ \\
\cline { 2 - 3 } & Turkey & $0.02+/-0.01$ \\
\hline
\end{tabular}

\begin{tabular}{|l|l|l|}
\hline \multirow{3}{*}{$\begin{array}{l}\text { Crop } \\
\text { Harvest }\end{array}$} & Corn & $4.49+/-0.45$ \\
\cline { 2 - 3 } & Soybeans & $4.74+/-0.47$ \\
\cline { 2 - 3 } & Alfalfa & $0.50+/-0.05$ \\
\hline Volatilization & Crops & $1.87+/-0.37$ \\
\cline { 2 - 3 } & $\begin{array}{l}\text { Fertilizer } \\
\text { Application }\end{array}$ & $0.59+/-0.12$ \\
\cline { 2 - 3 } & $\begin{array}{l}\text { Manure } \\
\text { Application }\end{array}$ & $0.04+/-0.01$ \\
\hline Stream Flow & & $2.43+/-0.24$ \\
\hline
\end{tabular}

Figure 3.

EISA nitrogen budget results. 


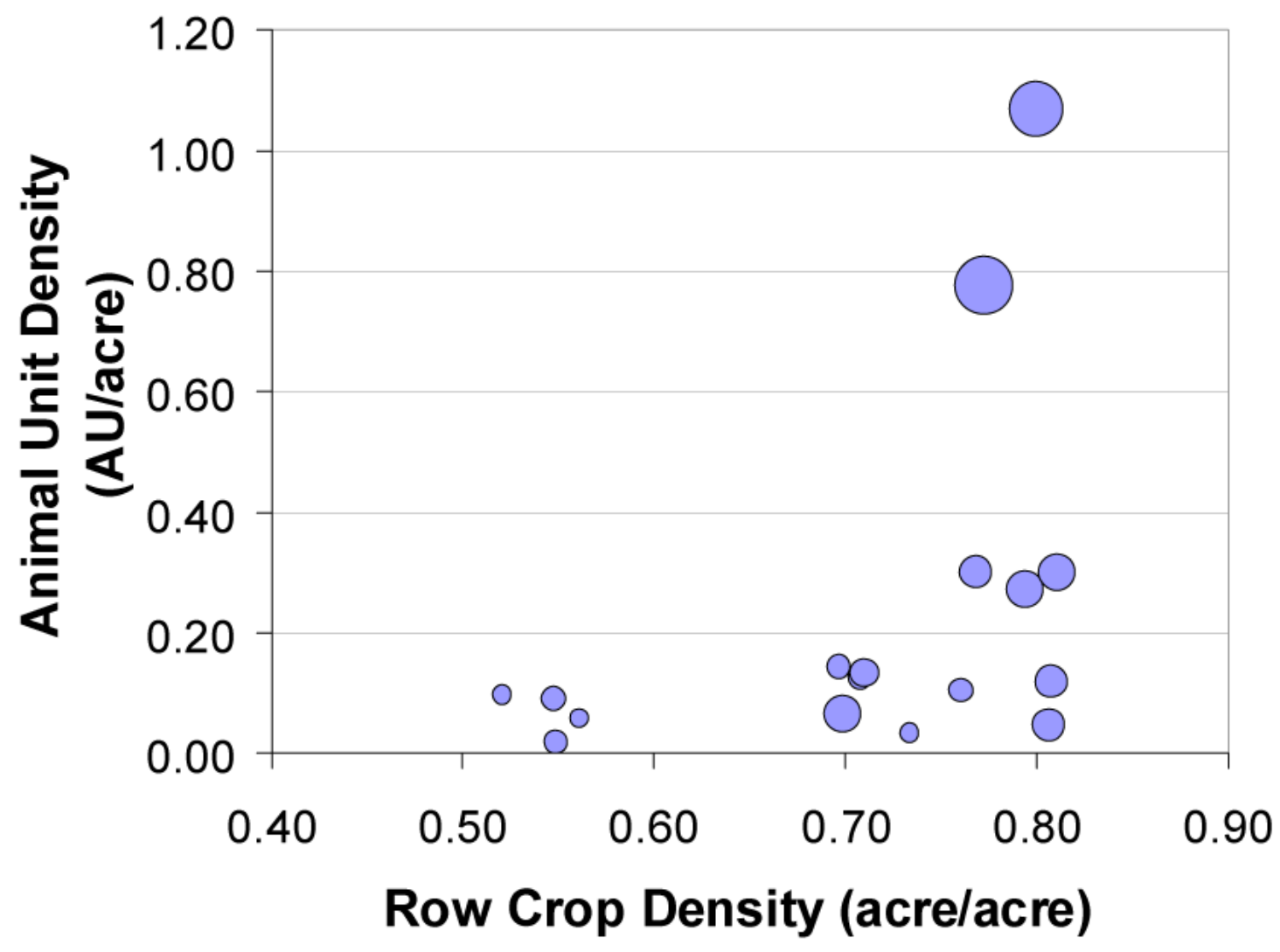

Figure 4.

Nitrate concentration (mg/l) shown as bubble size for 17 independent EISA monitoring stations. The smallest point represents $6.35 \mathrm{mg} / \mathrm{l}$. The largest point represents $15.8 \mathrm{mg} / \mathrm{l}$. 
Table 1

Watershed Comparison of the Number of Monitoring Stations and the Average Number of Months of Data Represented

\begin{tabular}{|c|c|c|}
\hline Watershed & $\begin{array}{l}\text { No. of Monitoring } \\
\text { Stations }\end{array}$ & Avg. Months of Data \\
\hline Cedar & 16 & 58.2 \\
\hline Iowa & 11 & 61.9 \\
\hline Skunk & 7 & 60.0 \\
\hline Wapsipinicon & 4 & 62.8 \\
\hline
\end{tabular}


